\title{
ELASTICITY FOR ECONOMIC PROCESSES WITH MEMORY: FRACTIONAL DIFFERENTIAL CALCULUS APPROACH
}

\author{
VAlentina V. TARASOVA AND VASILY E. TARAsov
}

Abstract. Derivatives of non-integer orders are applied to generalize notion of elasticity in framework of economic dynamics with memory. Elasticity of $Y$ with respect to $X$ is defined for the case of a finite-interval fading memory of changes of $X$ and $Y$. We define generalizations of point price elasticity of demand to the case of processes with memory. In these generalizations we take into account dependence of demand not only from current price (price at current time), but also all changes of prices for some time interval. For simplification, we will assume that there is one parameter, which characterizes a degree of damping memory over time. The properties of the suggested fractional elasticities and examples of calculations of these elasticities of demand are suggested.

Mathematics subject classification (2010): 26A33.

Keywords and phrases: Elasticity of functions, fractional derivative, processed with memory, price elasticity of demand.

\section{REFERENCES}

[1] S. G. Samko, A. A. Kilbas, O. I. Marichev, Integrals and Derivatives of Fractional Order and Applications, Nauka i Tehnika, Minsk, 1987; and Fractional Integrals and Derivatives Theory and Applications, Gordon and Breach, New York, 1993.

[2] A. A. Kilbas, H. M. SRivastava, J. J. Trujillo, Theory and Applications of Fractional Differential Equations, Elsevier, Amsterdam, 2006.

[3] I. Podlubny, Fractional Differential Equations, Academic Press, San Diego, 1998.

[4] D. Valerio, J. J. Trujillo, M. Rivero, J. A. Tenreiro Machado, D. Baleanu, Fractional calculus: A survey of useful formulas, The European Physical Journal. Special Topics., vol. 222, no. 8, (2013) 1827-1846.

[5] J. Tenreiro Machado, V. Kiryakova, F. Mainardi, Recent history of fractional calculus, Communications in Nonlinear Science and Numerical Simulation, vol. 16, no. 3, (2011) 1140-1153.

[6] J. A. Tenreiro Machado, A. M. S. F. Galhano, J. J. Trujillo, On development of fractional calculus during the last fifty years, Scientometrics, vol. 98, no. 1, (2014) 577-582.

[7] V. E. TARASOv, Fractional Dynamics: Applications of Fractional Calculus to Dynamics of Particles, Fields and Media, Springer, New York, 2011.

[8] J. Klafter, S. C. Lim, R. Metzler (Eds.), Fractional Dynamics. Recent Advances, World Scientific, Singapore, 2011.

[9] R. BAILLIE, Long memory processes and fractional integration in econometrics, Journal of Econometrics, vol. 73, no. 1, (1996) 5-59.

[10] E. Scalas, R. Gorenflo, F. Mainardi, Fractional calculus and continuous-time finance, Physica A, vol. 284, no. 1-4, (2000) 376-384.

[11] N. LAS KIn, Fractional market dynamics, Physica A, vol. 287, no. 3, (2000) 482-492.

[12] F. Mainardi, M. Raberto, R. Gorenflo, E. SCAlas, Fractional calculus and continuous-time finance II: The waiting-time distribution, Physica A, vol. 287, no. 3-4, (2000) 468-481, arXiv:condmat/0006454.

[13] R. Gorenflo, F. Mainardi, E. Scalas, M. Raberto, Fractional calculus and continuous-time finance III: the diffusion limit, In: M. Kohlmann, S. Tang, (Eds.) Mathematical Finance Trends in Mathematics, Birkhauser, Basel, 2001, pp. 171-180. 
[14] M. Raberto, E. Scalas, F. Mainardi, Waiting-times and returns in high-frequency financial data: an empirical study, Physica A, vol. 314, no. 1-4. (2002) 749-755, arXiv:cond-mat/0203596.

[15] M. M. Meerschaert, E. Scalas, Coupled continuous time random walks in finance, Physica A, vol. 370, no. 1, (2006) 114-118.

[16] J. A. Tenreiro Machado M. E. MatA, A fractional perspective to the bond graph modelling of world economies, Nonlinear Dynamics, vol. 80, no. 4, (2015) 1839-1852.

[17] J. A. Tenreiro Machado, M. E. Mata, Pseudo phase plane and fractional calculus modeling of western global economic downturn, Communications in Nonlinear Science and Numerical Simulation, vol. 22, no. 1-3, (2015) 396-406.

[18] J. A. Tenreiro Machado, M. E. Mata, A. M. Lopes, Fractional state space analysis of economic systems, Entropy, vol. 17, no. 8, (2015) 5402-5421.

[19] I. PodLubny, Geometric and physical interpretation of fractional integration and fractional differentiation, Fractional Calculus and Applied Analysis, vol. 5, no. 4, (2002) 367-386, arXiv:math/0110241.

[20] J. A. TENREIRO MACHADO, A probabilistic interpretation of fractional-order differentiation, Fractional Calculus and Applied Analysis, vol. 6, no. 1, (2003) 73-80.

[21] A. A. Stanislavsky, Probabilistic interpretation of the integral of fractional order, Theoretical and Mathematical Physics, vol. 138, no. 3, (2004) 418-431.

[22] V. E. TARASOv, Lattice fractional calculus, Applied Mathematics and Computation, vol. 257, (2015) $12-33$.

[23] V. E. TARasov, Exact discretization by Fourier transforms, Communications in Nonlinear Science and Numerical Simulation, 37 (2016) 31-61. (2016) accepted for publication, DOI: 10.1016/j.cnsns.2016.01.006.

[24] V. E. TARASOV, No violation of the Leibniz rule. No fractional derivative, Communications in Nonlinear Science and Numerical Simulation, vol. 18, no. 11, (2013) 2945-2948, arXiv:1402.7161.

[25] M. D. Ortigueira, J. A. Tenreiro Machado, What is a fractional derivative?, Journal of Computational Physics, vol. 293, (2015) 4-13.

[26] Cheng-SHi LiU, Counterexamples on Jumarie's two basic fractional calculus formulae, Communications in Nonlinear Science and Numerical Simulation, vol. 22, no. 1-3, (2015) 92-94.

[27] V. E. TARASOv, On chain rule for fractional derivatives, Communications in Nonlinear Science and Numerical Simulation, vol. 30, no. 1-3, (2016) 1-4.

[28] V. E. TARASOV, Local fractional derivatives of differentiable functions are integer-order derivatives or zero, International Journal of Applied and Computational Mathematics, 2 , 2 (2016) 195-201.

[29] V. E. TARASOV, Leibniz rule and fractional derivatives of power functions, Journal of Computational and Nonlinear Dynamics, vol. 11, no. 3, (2016) 031014.

[30] M. Bacharach, A. Dempster, J. Enos, (Eds.), Mathematical Models in Economics, Oxford University Press, Oxford, 1994.

[31] V. VOLTERRA, Theory of Functionals and of Integral and Integro-differential Equations, Dover, New York, 1959, Chapter VI, Section IV.

[32] C.-C. WANG, The principle of fading memory, Archive for Rational Mechanics and Analysis, vol. 18, no. 5, (1965) 343-366.

[33] J. C. Saut, D. D. Joseph, Fading memory, Archive for Rational Mechanics and Analysis, vol. 81, no. 1, (1983) 53-95. 